www.volsu.ru

DOI: http://doi.org/10.15688/nav.jvolsu.2017.2.5

UDC 902

LBC 63.4

\title{
SARMATIAN AND EARLY MEDIEVAL BURIAL MOUNDS OF THE EAST AZOV REGION (BASED ON SECURITY EXCAVATIONS IN 2014)
}

\author{
Yury Yu. Kargin \\ Archaeological expedition Ltd., Rostov-on-Don Region, Russian Federation \\ Vasiliy V. Mataev \\ Archaeological expedition Ltd., Rostov-on-Don Region, Russian Federation
}

\author{
Aleksey V. Surkov \\ Center of the security archaeological investigations Ltd., Voronezh, Russian Federation
}

\begin{abstract}
The article is devoted to the publication of security excavation materials of three burial mounds from the Peschanokop district of Rostov-on-Don region. Each burial mound contained only one looted tomb.

The tomb in the shaft-in-chamber from the mound Bogoroditsky IV with featureless inventory and western orientation belongs to sarmatian culture of the $3^{\text {rd }}-1^{\text {st }}$ century BC. Infill of the tomb contained parts of two unevenaged men's skulls, handmade pottery parts and a gray-clay wheeled bowl. The pottery has North-Caucasian origins, but it is not exactly dated.

The tomb from mound 6 of the burial mound Peschanokop belongs to the undermound Sarmatian catacombs dated by Roman period. A censer and a gray-clay wheeled bowl have meotian analogies, dated by the $2^{\text {nd }}$ century $\mathrm{AD}$. The dating of the tomb is confirmed by the golden pendant-medallions incrusted by the red carnelian insertion which belonged to the Greek-Roman polychrome style. The analogies are found in the Volga-Don and Kuban regions.

The tomb from mound 6 of the burial mound Peschanokop belongs to the Bulgarian variant of Saltov-Mayaki culture and is dated by the $8^{\text {th }}-9^{\text {th }}$ centuries $\mathrm{AD}$. The main features of the mound include the western orientation of the man's skeleton, horse remains in particular and parts of the sacrificial sheep, remains of the coffin and mat. There was also a shaft-in-chamber near the feet of deceased in the end wall - the feature of the proto-Bulgarian tombs.

The ways of the mound's looting are also various. A tomb from the burial mound Bogoroditsky IV was destructed with the triangulation station mark. Early medieval mound 7 of the burial mound Peschanokop was looted in ancient times with the excavated vertical shaft in the center, under the tomb. The Sarmatian catacomb of mound 7 was looted by the knowledgeable contemporary looters with only enrichment motivation. They got exactly into the shaft of the catacomb and pull out the bones and the artefacts from the burial chamber through the inlet. Although it might be a tomb desecration by the unfriendly families' members.

Key words: East Azov region, burial mound, Early Iron Age, early Middle Ages, Sarmatian cultures, Bulgarian variant of Saltov-Mayaki culture, looting.

Citation. Kargin Yu.Yu., Mataev V.V., Surkov A.V., 2017. Sarmatian and Early Medieval Burial Mounds of the East Azov Region (Based on Security Excavations in 2014). The Lower Volga Archaeological Bulletin, vol. 16, no. 2, pp. 77-92. (in Russian).

УДК 902

ББК 63.4
\end{abstract}

\section{САРМАТСКИЕ И РАННЕСРЕДНЕВЕКОВЫЙ КУРГАНЫ ВОСТОЧНОГО ПРИАЗОВЬЯ (ПО МАТЕРИАЛАМ ОХРАННЫХ РАСКОПОК 2014 г.)}

\author{
Юрий Юрьевич Каргин
}

ООО «Археологическая экспедиция», Ростовская область, Российская Федерация 
Yu.Yu. Kargin, V.V. Mataev, A.V. Surkov. Sarmatian and Early Medieval Burial Mounds of the East Azov Region

Василий Владимирович Матаев

ООО «Археологическая экспедиция», Ростовская область, Российская Федерация

Алексей Владимирович Сурков

ООО «Центр охранных археологических исследований», г. Воронеж, Российская Федерация

Аннотация. Статья посвящена публикации материалов охранных раскопок трех курганов в Песчанокопском районе Ростовской области, в которых исследовано по одному ограбленному захоронению.

Погребение в подбое из кургана Богородицкий IV с невыразительным инвентарем и западной ориентировкой относится к кругу памятников сарматской культуры III-I вв. до н.э. В заполнении встречались фрагменты черепов двух разновозрастных мужчин, фрагменты лепного сосуда и круговая сероглиняная миска. Посуда имеет северокавказское происхождение, но не позволяет сузить датировку.

Погребение из кургана 6 могильника Песчанокоп относится к числу подкурганных сарматских катакомб римской эпохи. Курильница и круговая сероглиняная миска имеют меотские аналогии, датируемые II в. н.э. Датировку комплекса подтверждают золотые подвески-медальоны с сердоликовыми вставками греко-римского полихромного стиля, встречающиеся в Волго-Донском междуречье и Прикубанье.

Погребение из кургана 7 могильника Песчанокоп может быть отнесено к болгарскому варианту салтово-маяцкой культуры и датировано VIII-IX вв. Среди характеризующих его признаков - западная с южным отклонением ориентировка мужского костяка, положение в могилу костей конечностей коня и части туши жертвенного барана, остатки гробовища и подстилки. В торцевой стенке со стороны ног погребенного имеется небольшой подбой, что также отмечается в некоторых протоболгарских захоронениях.

Разнообразны и способы ограбления вышеописанных курганов. В кургане Богородицкий IV погребение было повреждено при установке триангуляционного знака. Раннесредневековый курган 7 могильника Песчанокоп был ограблен в древности с помощью выкапывания простого вертикального лаза над погребением. В случае с сарматским погребением из кургана 6 грабители точно попали во входную шахту катакомбы и вытащили кости и вещи из погребальной камеры через входное отверстие. Очевидно, это ограбление было совершено осведомленными современниками, преследовавшими сугубо материальные цели. Тем не менее нельзя исключить и целенаправленное осквернение захоронения представителями недружественных семей.

Ключевые слова: восточное Приазовье, курган, ранний железный век, раннее средневековье, сарматские культуры, болгарский вариант салтово-маяцкой культуры, ограбление.

Цитирование. Каргин Ю. Ю., Матаев В. В., Сурков А. В., 2017. Сарматские и раннесредневековый курганы Восточного Приазовья (по материалам охранных раскопок 2014 г.) // Нижневолжский археологический вестник. Т. 16, № 2. С. 77-92.

Осенью 2014 г. экспедиция ООО «Археологическое общество Кубани» по открытому листу, выданному на имя А.В. Суркова, проводила охранные раскопки курганов на территории Песчанокопского района Ростовской области. При помощи бульдозера было раскопано 3 небольших индивидуальных кургана с погребениями раннего железного века и раннего средневековья. Антропологические определения выполнены Р.А. Тюриным. Полученные материалы были переданы на хранение в ГБУК ВО Природно-археологический музей-заповедник «Дивногорье» (г. Воронеж).

\section{Курганный могильник Богородицкий IV}

Курганный могильник «Богородицкий IV» (рис. 2,1) выявлен в 2011 г. экспедицией
ОАО «Наследие Кубани» и ГАУК РО «Донское наследие» под руководством М.В. Власкина. Памятник состоял из одной насыпи, расположенной на водоразделе р. Средний Егорлык и балки Безымянка, в 6,5 км к ЮЗ от с. Богородицкое, на пахотном поле, ограниченном густыми лесополосами.

Насыпь округлой в плане формы, высотой 0,7 м и диаметром до 20 м (рис. 3,1 ). На вершине ранее был установлен триангуляционный знак, спиленный впоследствии, поэтому распашке подвергались лишь полы кургана, а центр остался нетронутым. Металлическая вышка была сооружена на базе крупной бетонной «матки», яма под которую нарушила поверхность материка и центральное погребение.

Для стратиграфических наблюдений была оставлена центральная бровка, ориен- 
тированная по линии С-Ю. В 9 м к В от нее дополнительно была оставлена восточная бровка. По итогам раскопок установлено, что размеры древней курганной насыпи, вытянутой по направлению 3-В, составляли $13 \times 16$ м, а высота $-0,72$ м. Наиболее показателен восточный фас центральной бровки, в котором была зафиксирована яма, вырытая для установки триангуляционного знака, протяженностью до 2,44 м. В 3 м к С от нее, под слоем дерна, в насыпи прослеживался пробой мусорной ямы глубиной 1,12 м от $R_{0}$. На дне этой ямы был обнаружен скелет собаки, фрагменты разбитого чугунка и несколько камней.

В ходе разбора насыпи на уровне материка, в 1,1 м к В от ее центра, обнаружено пятно единственного погребения, юго-западная часть которого была разрушена при установке триангуляционного знака.

Погребение 1 (рис. 3,2). Яма погребения ориентирована по оси 3-В. В северной стенке ямы зафиксированы подбой и ведущая в него ступенька, разрушенные при сооружении триангуляционного знака. Зафиксированная длина ямы $-2,4$ м, наибольшая ширина 2,5 м, ее заполнение - плотное, затечное, состоявшее из материкового суглинка светложелтого цвета, перемешанного с комками темной супеси. В заполнении встречены следы дерева, обломки костей человека, фрагменты костей барана.

Площадка перед ступенькой в подбой (южная часть ямы) находилась на глубине 1,76 м от $R_{0}$. Ступенька располагалась параллельно дну разрушенного подбоя, ее высота достигала 0,3 м. Узкое дно подбоя ориентировано по направлению ЗЮЗ-ВСВ, его ширина $-0,96$ м, длина $-3,26$ м. Свод подбоя сохранился только в восточной части ямы, его высота - 0,43 м. После зачистки подбоя общая длина ниши по дну составила 3,07 м.

Яма для закладки бетонной «матки» триангуляционного знака прорезала южную часть ямы погребения и имела квадратную форму, заглубляясь в материк до 2,21 м от $R_{0}$. На дно этой ямы были горизонтально уложены друг на друга 2 бетонные квадратные «подушки» размерами $55 \times 55 \times 15$ см, на которые сверху поставлен усеченно-пирамидальный столбик с квадратными основанием $(35 \times 35$ см $)$ и вер- шиной $(25 \times 25$ см). Верхняя часть столбика была зафиксирована на глубине 1,29 м от $R_{0}$.

Обломки костей человека отмечены в заполнении ямы и в подбое. У западной узкой стенки входной ямы и в заполнении встречались фрагменты черепа. In situ сохранилась только большая и малая берцовые кости, которые лежали в восточной части подбоя. По данным антропологического анализа, в погребении присутствовали кости двух мужчин в возрасте 35-40 лет и старше 50 лет. У первого на верхнем крае глазниц и в правой ушной раковине отмечалась крибра (холодовый стресс, отит?). Очевидно, что погребение было разграблено еще до установки триангуляционного знака.

\section{Инвентарь.}

1. Круговая сероглиняная острореберная миска (рис. 5,1). Стояла на дне подбоя, у дальней стенки. Бортик миски загнут вовнутрь, переход к стенкам тулова выделен ребром. От ребра округло-выпуклые стенки довольно резко сужаются к плоскому дну. Диаметр миски по ребру - 34,4 см, диаметр по краю венчика - 31,2 см, диаметр расслоившегося дна 14 см. Вблизи от трещины, протянувшейся через весь корпус, имеются следы ремонта: просверленные с обеих сторон от нее, ниже ребра, круглые сквозные отверстия диаметром около 0,3 см. Поверхность миски, в особенности внешняя, хорошо залощена. Обжиг плохой, неравномерный. Поверхность - серо-коричневого, близкого к кирпичному цвета. На серой внешней поверхности имеются пятна копоти. Излом черепка серый, слоистый, с незначительной примесью толченой раковины моллюска и песка.

2. Фрагмент прямого венчика черноглиняного сосуда (рис. 5,2). Обнаружен в западной части заполнения строительной ямы на глубине 2 м от $R_{0}$. Фрагмент относится к сосуду хорошего обжига, его размеры $3,3 \times 3,6 \mathrm{~cm}$, толщина $-0,7 \mathrm{~cm}$.

3. Два фрагмента железистой конкреции (?) зафиксированы возле миски.

\section{Курганный могильник Песчанокоп}

Курган № 1 курганного могильника «Песчанокоп» выявлен в 1994 г. В.Я. Кияшко при проведении инвентаризации памятников архе- 
ологии Ростовской области. В 2011 г. экспедицией ОАО «Наследие Кубани» и ГАУК РО «Донское наследие» под руководством М.В. Власкина дополнительно выявлены еще 7 курганов (№ 2-8).

Цепочка курганов, расположенных в 6,5 км к ЗЮЗ от р.п. Песчанокопское, тянется по направлению ВСВ-ЗЮЗ по водоразделу р. Рассыпная и пруда Войков (рис. 2,2). Курганы находятся на пахотном поле, ограниченном с 3 лесополосой, вдоль которой проложена ВЛ с бетонными опорами.

В 2014 г. были раскопаны курганы № 6 и 7, находящиеся к В от лесополосы, в западной части могильника, и попадающие в зону проектируемого строительства. Оба кургана были ограблены еще в древности.

\section{Курган 6}

Распаханная насыпь кургана округлой в плане формы, высота - 0,1 м, диаметр - 15 м (рис. 4,1).

Для стратиграфических наблюдений была оставлена центральная бровка, ориентированная по направлению С-Ю. В ходе раскопок установлено, что диаметр древней насыпи составлял 13,1 м, а сохранившаяся высота $-0,96$ м. В южной части насыпи под слоем пашни отмечены пробои насыпи до материка. Первый находился в 2,08 м к Ю от условного центра кургана, его ширина в верхней части составляла 1,76 м, в нижней $-0,8$ м. Второй пробой находился в 4,84 м к Ю от центра, его ширина в верхней части составляла 1 м, в нижней - 0,24 м. Заполнение пробоев - темно-серый затечный суглинок.

В ходе разбора насыпи на уровне материка, в 1,7 м к С3 от ее центра, было обнаружено пятно входной шахты погребения, разрушенной грабительской ямой.

Погребение 1 (рис. 4,2) оказалось единственным в кургане. Входная шахта погребения - продолговатая, ориентирована длинной осью по направлению С-Ю, стенки вертикальные, отвесные. Длина шахты 2,22 м, ширина $-0,81$ м, глубина - 1,03 м от зафиксированной поверхности материка $\left(2,08\right.$ от $\left.R_{0}\right)$. В северной сужающейся стенке входной шахты заметно округлое отверстие размерами $0,55 \times 0,67$ м с признаками расши- рения в процессе ограбления. Входное отверстие вело через порожек высотой 7 см и шириной 10 см в обширную погребальную камеру, вырытую в материковом грунте. Камера трапециевидная в плане, с закругленными углами и вертикальными стенками с плавным переходом в свод. Размеры камеры: длина 2,24 м, ширина в южной части $-1,34$ м, в северной - 1,04 м, высота свода - до 0,89 м.

В северо-западной части дна входной шахты, в 0,5 м от входного отверстия, обнаружено пятно прокала красноватого оттенка размерами 0,16 × 0,08 см. Вероятно, прокал остался от светильника, которым пользовались грабители. Следы органического тлена пепельного цвета проявились при зачистке дна в северной части шахты. Такие же следы зафиксированы отдельными небольшими пятнами на дне погребальной камеры, по краям которой также отмечались фрагменты дерева.

Заполнение входной шахты - плотное, затечное. Оно состояло из материкового суглинка светло-желтого цвета, перемешанного с комочками темной супеси. При разборе заполнения встречались фрагменты дерева и угольки, обломки и целые кости человека, а также фрагментированные кости барана. На дне входной шахты расчищены беспорядочно разбросанные кости человека, принадлежавшие женщине в возрасте свыше 50 лет: длинные кости, ребра, позвонки, тазовая кость и т. д. В дальнейшем было установлено, что почти весь скелет был извлечен из погребальной камеры по частям через входное отверстие при ее ограблении. В погребальной камере, в 1,34 м к СВ от входа, остался лишь череп, нижняя челюсть и тазовая кость, а вблизи входа - еще несколько разрозненных костей.

\section{Инвентарь.}

1. Лепная курильница-вазочка (рис. 5,3). Зафиксирована в заполнении входной шахты, у восточной стенки, на глубине 1,89 м от $R_{0}$. Курильница представляет собой вазочку с коническим корпусом, короткой цилиндрической ножкой, чуть расширяющейся у основания. Основание круглое, с асимметричным углублением в центре. Высота курильницы $-4,9$ см, диаметр венчика $-8,9$ см, диаметр основания ножки $-3,3 \times 3,1$ см. Поверхность серая, край венчика сильно закопчен, черепок чер- 
ный в изломе. На внутренней стороне вазочки видны полосы от заглаживания.

2. Круговая сероглиняная миска со сглаженным ребром и выделенным венчиком (рис. 5,4). Обнаружена в верхних слоях заполнения входной шахты, ближе к юго-западной стенке, на глубине 1,6 м от $R_{0}$. Бортик миски прямой, чуть загнутый вовнутрь, край выделенного венчика утолщенный, нависает над бортиком, срез округленный. Ниже сглаженного ребра стенки резко сужаются к слабовогнутому, чуть приподнятому дну. Ниже реб$\mathrm{pa}$, на внутренней поверхности, сохранились следы от работы на гончарном круге, на внешней поверхности - слабозаметные следы сглаживания. Черепок плотный с незначительной примесью песка. На дне имеется пятно черного нагара. Диаметр миски по заглаженному ребру - 28,2 см, диаметр утолщенного края 27,8 см, диаметр дна $-12,8$ см, высота миски $-8,5$ см.

3. Золотые подвески-медальоны с инкрустацией из обработанного красного сердолика, 3 экз. (рис. 5,5). Обнаружены в заполнении ямы на разной глубине среди отброшенных грабителями костей человека и барана. Подвески-медальоны однотипные, квадратноокруглой формы. Основание подвесок представлено тонкой пластинкой. Ее тыльная сторона неровная, с вмятинами и выступами изза давления, оказывавшегося на изделие в процессе изготовления. К тыльной стороне пластинки-основания одним концом припаяны два кольца для подвешивания, изготовленные из тонкой ленты с двумя продольными ложбинками. Второй конец обеих лент плавно загнут, сечением вплотную касаясь их внутренней поверхности. У одной из подвесок припаянные концы лент имеют срезанные углы. Внешняя сторона подвески оформлена прямоугольным кабошоном камня с хорошо заполированной поверхностью. Кабошон удерживается прямоугольной обоймой. Бортик пластинки закругленный, гладкий. На пространство между обоймой и бортиком по периметру припаяно несколько взаимовложенных колец сканной проволоки, концами стыкующихся в пространстве между кольцами для подвешивания. У двух подвесок-медальонов напаяно 3 кольца сканной проволоки и одно внешнее - прямой проволоки того же сечения. Вставки у них с лицевой и тыльной сторон имеют округленные поверхности в первом случае и с округленным горизонтальным ребром - во втором: в обоих случаях они отпечатались с обратной стороны на пластине-основании. У третьего изделия на пространство между обоймой и бортиком по периметру припаяно 4 кольца сканной проволоки, на нем же сердоликовая вставка имеет ромбическую полированную площадку на обеих сторонах, причем с обратной стороны она также отпечаталась на пластине-основании; образовавшиеся при этом углы скошены ровной полировкой. Длина пластинок $-2-2,1$ см, ширина $-1,7-1,8$ см, толщина $-0,1$ см, ширина лент $-0,25$ см, диаметр колец $-0,5$ см. Длина сердоликовых вставок - 1,1-1,2 см, ширина $-0,8-1$ см, высота - около $0,3-0,4$ см.

4. Фрагменты лепного черноглиняного сосуда (рис. 5,6) встречены в заполнении входной шахты на разной глубине. Черепок тонкостенный, с хорошо заглаженной поверхностью. Глина темная в изломе, хорошего обжига, с незначительной примесью песка. На внутренней поверхности отмечены следы нагара, на внешней - большое черное пятно нагара. Размер самого большого черепка $-9,1 \times 8,9 \mathrm{~cm}$, толщина $-0,6$ см. Форма сосуда не восстанавливается.

5. Мелкие фрагменты предмета из дерева. Зафиксированы на глубине 1,7 м от $R_{0}$. Предмет неясного назначения, рассыпался при извлечении.

6. Мелкие фрагменты железного предмета встречены в заполнении входной ямы на разной глубине. Наиболее крупный фрагмент представляет собой изогнутый под углом кусок стержня (крюк?) со следами гнилых деревянных волокон в месте изгиба.

\section{Курган 7}

Курган 7 находился в 20 м к ЮЗ от кургана 6. Распаханная насыпь кургана округлой в плане формы, высота - 0,1 м, диаметр - 15 м (рис. 6,1).

Для стратиграфических наблюдений была оставлена центральная бровка, ориентированная по направлению С-Ю. В ходе раскопок установлено, что диаметр древней насыпи составлял 12,5 м, а сохранившаяся вы- 
сота $-0,8$ м. В 1,2 м к Ю от условного центра кургана в насыпи зафиксирована грабительская яма протяженностью 1,5 м в верхней части и 1,2 м - на уровне материка. Заполнение ямы - плотный темно-серый затечный суглинок.

В ходе разбора насыпи на уровне материка, в 1 м к Ю от ее центра, под центральной бровкой, было обнаружено пятно единственного погребения, разрушенного грабительской ямой.

Погребение 1 (рис. 6,2). Прямоугольная узкая яма погребения с закругленными малыми сторонами и, возможно, со ступенькой ориентирована по оси ЗЮЗ-ВСВ. Длина ямы 2,05 м, максимальная ширина - 1,24 м, глубина $-0,7$ м от поверхности материка $(1,77$ м от $\left.R_{0}\right)$. Южная стенка ямы разрушена грабительской ямой, которая фиксируется до глубины 1,79 м от $R_{0}$. В северо-восточной торцевой стенке зафиксирован небольшой подбой глубиной около $0,2 \mathrm{M}$.

Заполнение погребальной камеры плотное, затечное, сложенное материковыми комками светло-желтого цвета, перемешанными с темно-серой супесью. В заполнении на разной глубине встречены следы древесного тлена и фрагменты костей одной особи барана. На дне ямы отмечены пятна органического тлена светло-пепельного цвета. Два небольших фрагмента дерева найдены в северо-восточной части могильной ямы.

Скелет погребенного разрушен грабительским перекопом. Кости человека (плечевая, лопатка, нижняя челюсть, ребра и позвонки) найдены в заполнении ямы на разной глубине. Фрагментированная нижняя челюсть находилась у юго-западной стенки ямы. По данным антропологического анализа погребенный - мужчина в возрасте 35-40 лет.

Инвентарь.

1. Небольшие фрагменты железного предмета. Один фрагмент зафиксирован у северной стенки ямы, другой - у южной. Фрагменты подверглись сильному коррозионному разложению, реконструировать изделия не представляется возможным.

2. Две передние и задняя конечности лошади, лежащие в анатомическом сочленении, обнаружены на дне северо-восточной части ямы, в ногах погребенного.
$* * *$

В трех курганах, раскопанных в 2014 г. в Песчанокопском районе Ростовской области, исследовано по одному ограбленному захоронению. Выявленные особенности погребальной обрядности и сохранившиеся находки позволяют осуществить их культурно-хронологическую интерпретацию.

Погребение в подбое из кургана Богородицкий IV относится к кругу сарматских памятников. Сам подбой обширнее входной ямы и больше нее по своей длине, что позволяет определить его как вариант Б подбоев типа II по К.Ф. Смирнову [Смирнов, 1972, с. 74]. Подбойные могилы известны в сарматское время на Нижнем Дону и в Прикубанье, при этом западная ориентировка считается типичной чертой погребального обряда кочевников IIIІ вв. до н.э. [Виноградов, 1965, с. 109; Смирнов, 1974, с. 41; Марченко, 1996, с. 100-105]. Несмотря на то что в могиле in situ зафиксированы кости ног только одного человека, в заполнении встречены фрагменты черепов двух разновозрастных мужчин, что может указывать на коллективный характер захоронения. Наиболее показательной из находок является лощеная сероглиняная острореберная миска с плоским дном, изготовленная на медленно вращающемся гончарном круге. По морфологическим особенностям и составу теста она относится к изделиям керамических мастерских центральных районов Северного Кавказа того же широкого хронологического диапазона [Мошкова, 1980, с. 50-51; Гугуев, Малашев, Рылов, 2017]. Имеющиеся данные, к сожалению, не позволяют сузить датировку публикуемого комплекса.

Погребение из кургана 6 могильника Песчанокоп относится к числу подкурганных сарматских катакомб римской эпохи, а именно к типу II по К.Ф. Смирнову. По мнению исследователя, катакомбы такой конструкции появляются и получают распространение на Нижнем Дону и Северном Кавказе на рубеже нашей эры [Смирнов, 1972, с. 73-81]. С.И. Безуглов определяет верхнюю хронологическую границу катакомб этого типа на Дону IV в. н.э. [Безуглов, 2008, с. 286]. Происходящие из исследуемого комплекса круговая сероглиняная миска с краем, нависающим над бортиком, и 
лепная курильница-вазочка, судя по всему, имеют меотское происхождение и позволяют сузить датировку погребения. Согласно исследованиям сероглиняной керамики некрополя Кобякова городища, проведенным В.М. Косяненко, миски такого типа массово появляются на рассматриваемой территории в I в. н.э. и существуют вплоть до конца II века. В нашем случае соотношение диаметра устья миски и высоты превышает величину $3: 1$, что указывает на ее позднюю датировку в пределах II в. н.э. [Косяненко, 1989, с. 28]. Не противоречат этому выводу и морфологические особенности курильницы-вазочки, аналогии которой известны среди меотских материалов Нижнего Дона [Косяненко, 2008, с. 303, 304, рис. $31,3,32,1]$. Датировку комплекса подтверждают золотые подвески-медальоны с сердоликовыми вставками греко-римского полихромного стиля [Засецкая, 2008, с. 12-13]. Аналогичные изделия происходят из погребения в кургане на горе «Можары» в 11 верстах от слободы Котовой, на территории современного Котовского района Волгоградской области [Отчет..., 1901, с. 77], из погребения 2 кургана 13 могильника Большая Дмитриевка-I в Лысогорском районе Саратовской области [Матюхин, 1991], а также из катакомбных погребений «Золотого кладбища» на Средней Кубани [Гущина, Засецкая, 1992] ${ }^{1}$. Таким образом, погребение из кургана 6 могильника Песчанокоп по всем признакам можно отнести к кругу сарматских памятников II в. н.э.

Погребение из кургана 7 могильника Песчанокоп может быть отнесено к болгарскому варианту салтово-маяцкой культуры и датировано VIII-IX веками. Среди характеризующих его признаков - западная с южным отклонением ориентировка мужского костяка в подбое, положение в могилу костей конечностей коня и части туши жертвенного барана, остатки гробовища и подстилки [Флерова, 2001, с. 165-166]. В торцевой стенке со стороны ног погребенного имелся небольшой подбой, что также отмечается в некоторых про- тоболгарских захоронениях [Аксенов, Тортика, 2001, с. 203]. При этом нетипичным представляется отсутствие ровика у кургана.

Разнообразны и способы ограбления вышеописанных курганов. В кургане Богородицкий IV погребение было повреждено при установке триангуляционного знака. Возможно, какие-то вещи были изъяты именно в это время. Раннесредневековый курган 7 могильника Песчанокоп был ограблен с помощью выкапывания простого вертикального лаза над погребением. Судя по отсутствию следов этого лаза на поверхности и затечности грунта в его заполнении, ограбление было совершено в древности.

Существенно больший интерес вызывает способ ограбления кургана 6 этого же могильника. Очевидно, грабители понимали, где находилось погребение и с какой погребальной обрядностью оно было совершено. На наш взгляд, только этим можно объяснить точное попадание небольшой грабительской ямы во входную шахту катакомбы и вытаскивание костей и вещей из погребальной камеры именно через входное отверстие. Земля из погребальной камеры, по-видимому, не просеивалась, поэтому не все золотые предметы были выявлены и изъяты грабителями. Во входной шахте, помимо беспорядочно разбросанных костей, остались миска с курильницей и фрагменты разбитого сосуда. С.А. Яценко и Е.В. Вдовченков отмечают частую встречаемость схожей методики разграбления средне- и позднесарматских степных курганов и трактуют ее как действия осведомленных современников, преследовавших сугубо материальные цели, однако не исключают и целенаправленное осквернение захоронений представителями недружественных семей [Яценко, Вдовченков, 2013, c. 85-88].

Таким образом, полученные материалы позволяют дополнить представление о погребальной обрядности сарматских и раннесредневековых племен восточного Приазовья, а также о времени и способах разграбления курганов. 


\section{ИЛЛЮСТРАЦИИ}

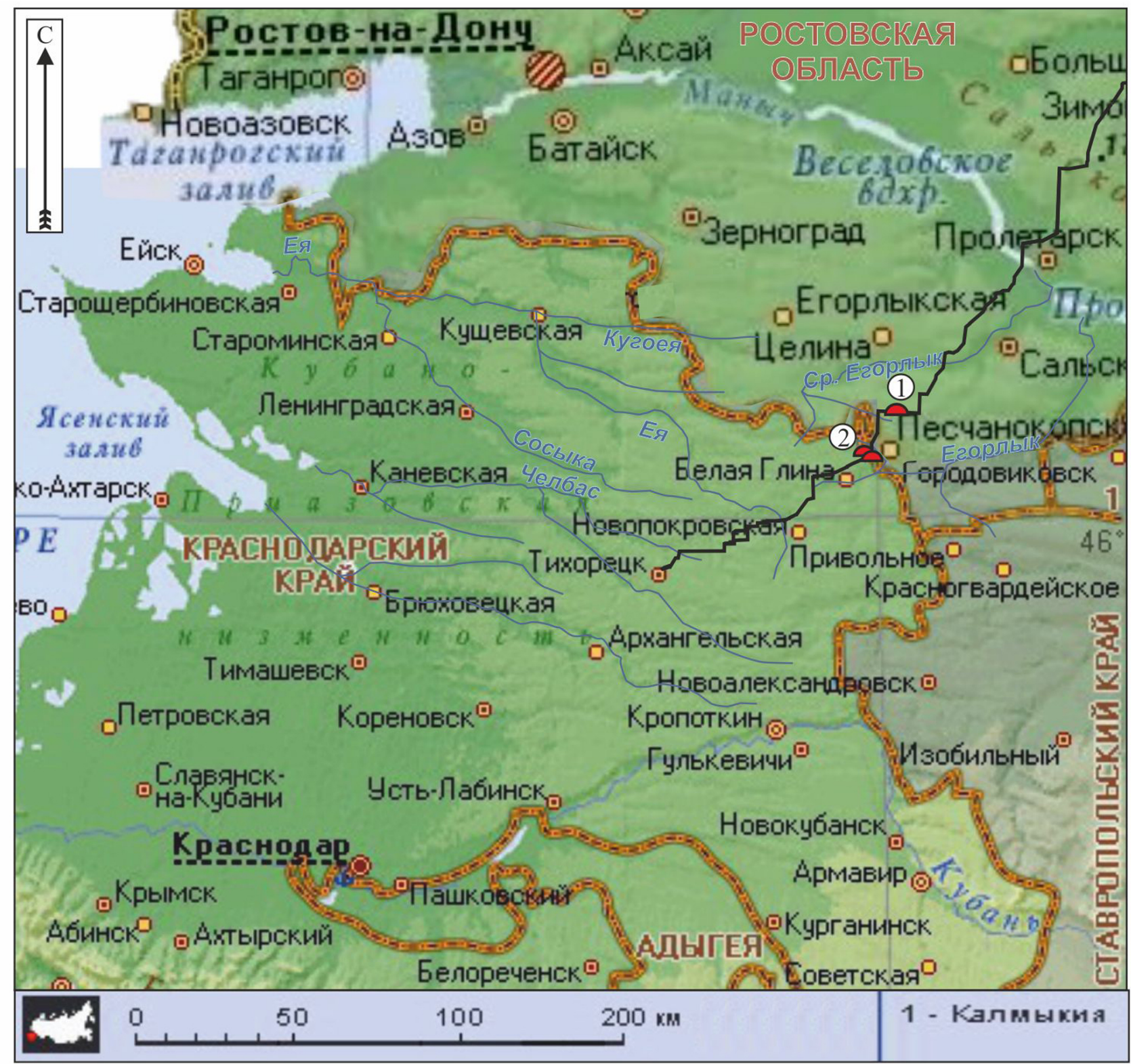

- проектируемая трасса ВЛ 500 кВ Ростовская АЭС - Тихорецкая 2 с расширением ПС 500 кВ Тихорецкая

1 - курганный могильник Богородицкий IV (1 насыпь)

2 - курганный могильник Песчанокоп (8 насыпей)

Рис. 1. Схема расположения курганных могильников Богородицкий IV и Песчанокоп в восточном Приазовье

Fig. 1. Scheme of location of burial mounds Bogoroditsky IV and Peschanokop in the area of the East Azov region 

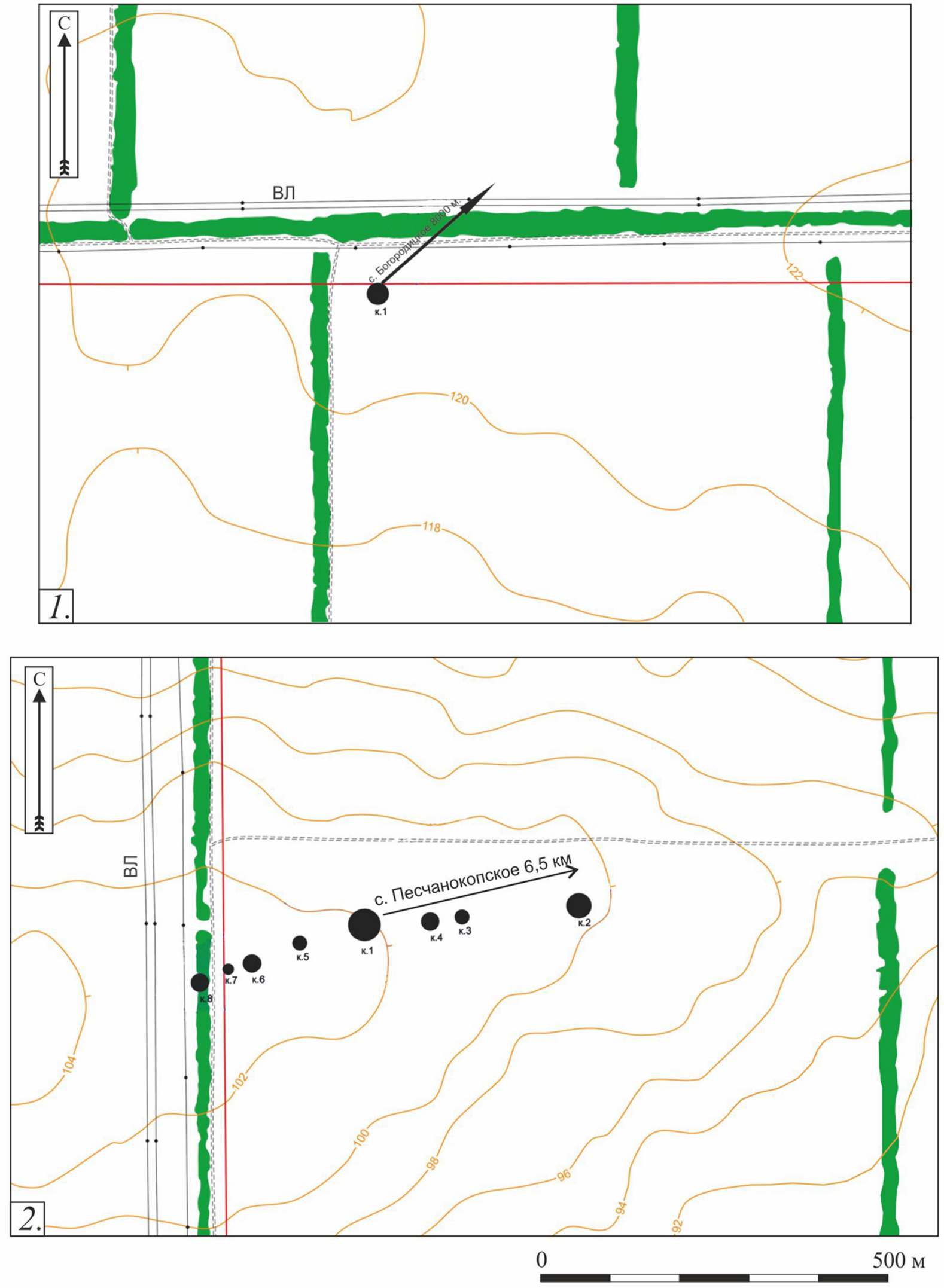

Рис. 2. Топографические планы курганных могильников:

1 - Богородицкий IV; 2 - Песчанокоп

Fig. 2. The topographic plans of the burial mounds:

1 - Bogoroditsky IV; 2 - Peschanokop 

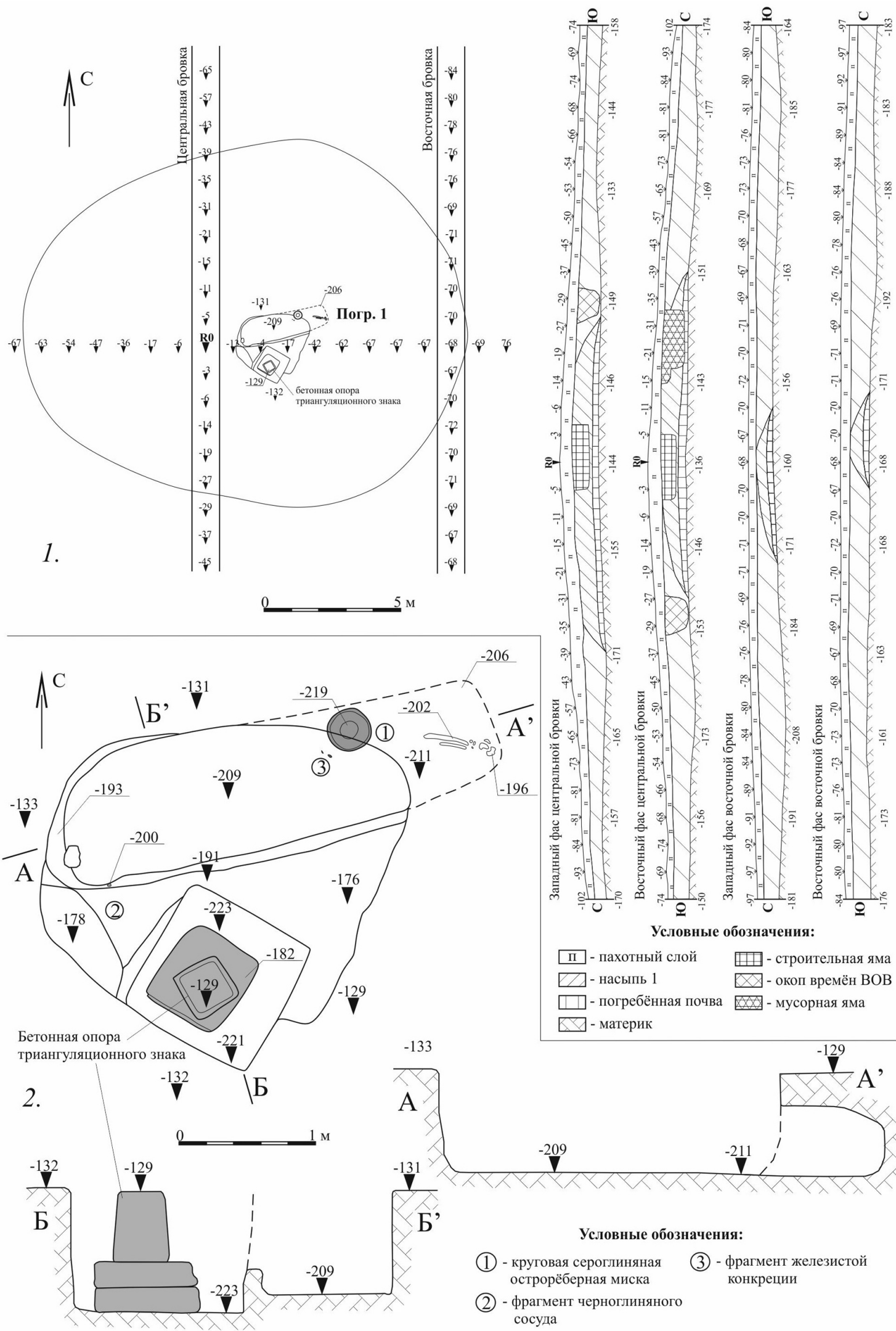

Рис. 3. Курганный могильник Богородицкий IV:

1 - план и стратиграфия кургана; 2 - погребение 1

Fig. 3. The burial mound Bogoroditsky IV:

1 - plan and stratigraphy; 2 - burial 1 

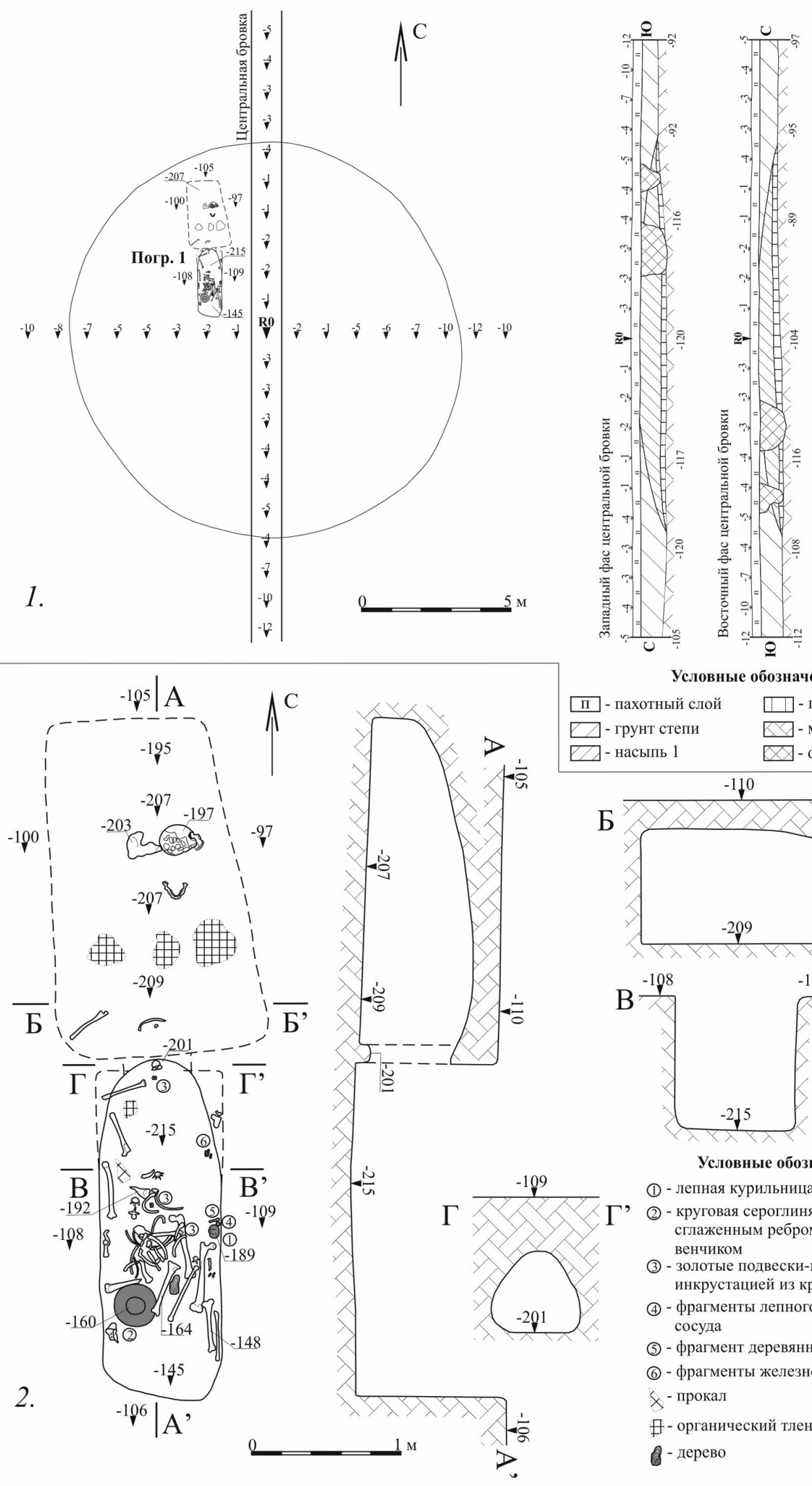

Условные обозначения:
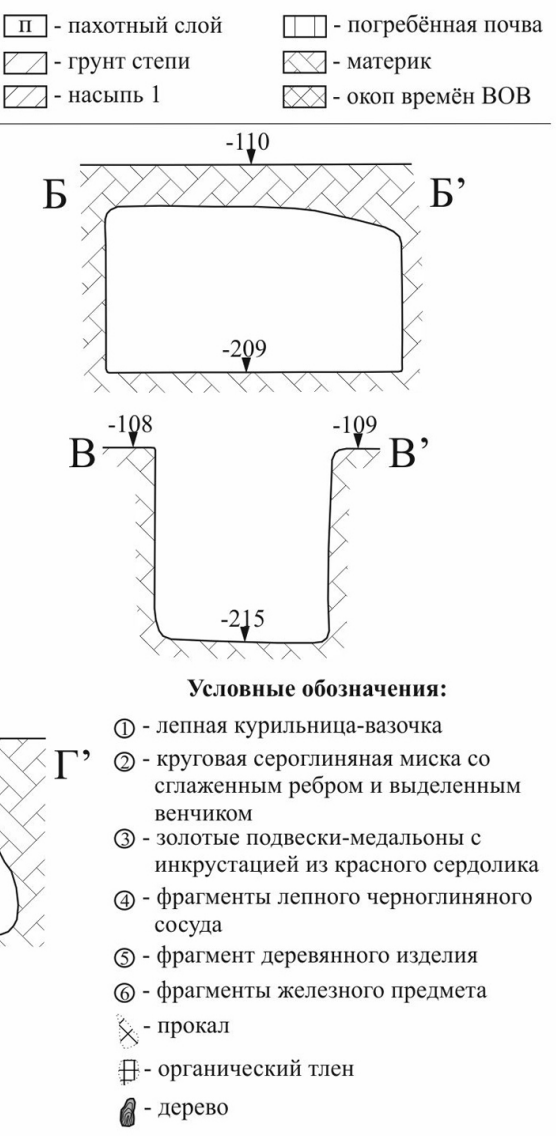

Рис. 4. Курганный могильник Песчанокоп. Курган 6:

1 - план и стратиграфия кургана; 2 - погребение 1

Fig. 4. The burial mound Peschanokop. Mound 6:

1 - plan and stratigraphy; 2 - burial 1 

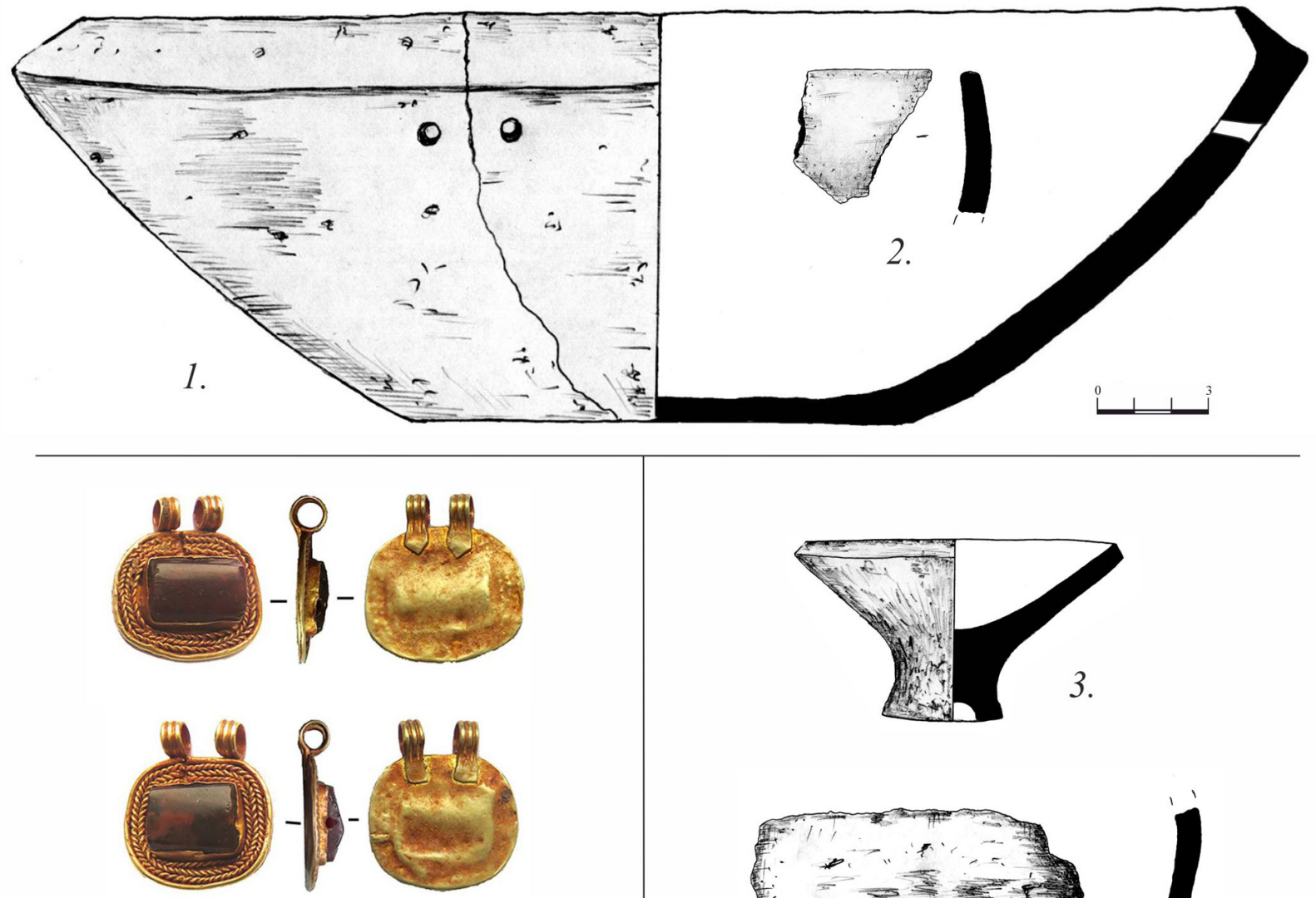

5.
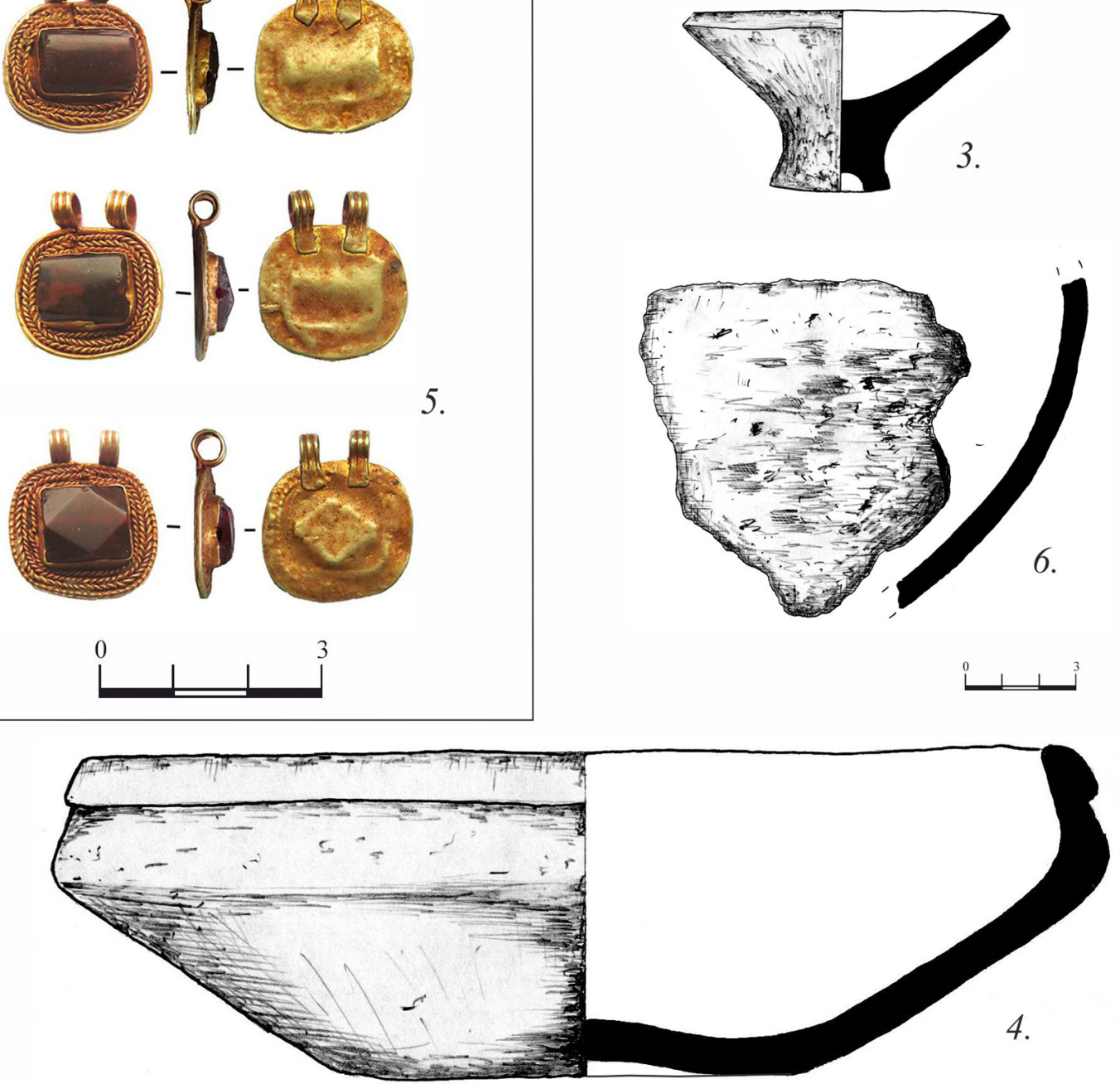

Рис. 5. Находки из погребений: 1-2 - курганный могильник Богородицкий IV; 3-6- курганный могильник Песчанокоп, курган 6:

1 - круговая сероглиняная миска; 2 - фрагмент сероглиняного сосуда; 3 - лепная курильница-вазочка; 4 - круговая сероглиняная миска; 5 - золотые подвески-медальоны с инкрустацией из красного сердолика; 6 - фрагмент лепного черноглиняного сосуда

Fig. 5. The artefacts from the burials: $1-2-$ burial mound Bogoroditsky IV; 3-6-burial mound Peschanokop, mound 6:

1 - gray-clay wheeled bowl; 2 - part of gray-clay vessel; 3 - handmade censer; 4 - gray-clay wheeled bowl; 5 - golden pendant-medallions incrusted by the red carnelian insertion; 6 - part of the handmade black-clay vessel 

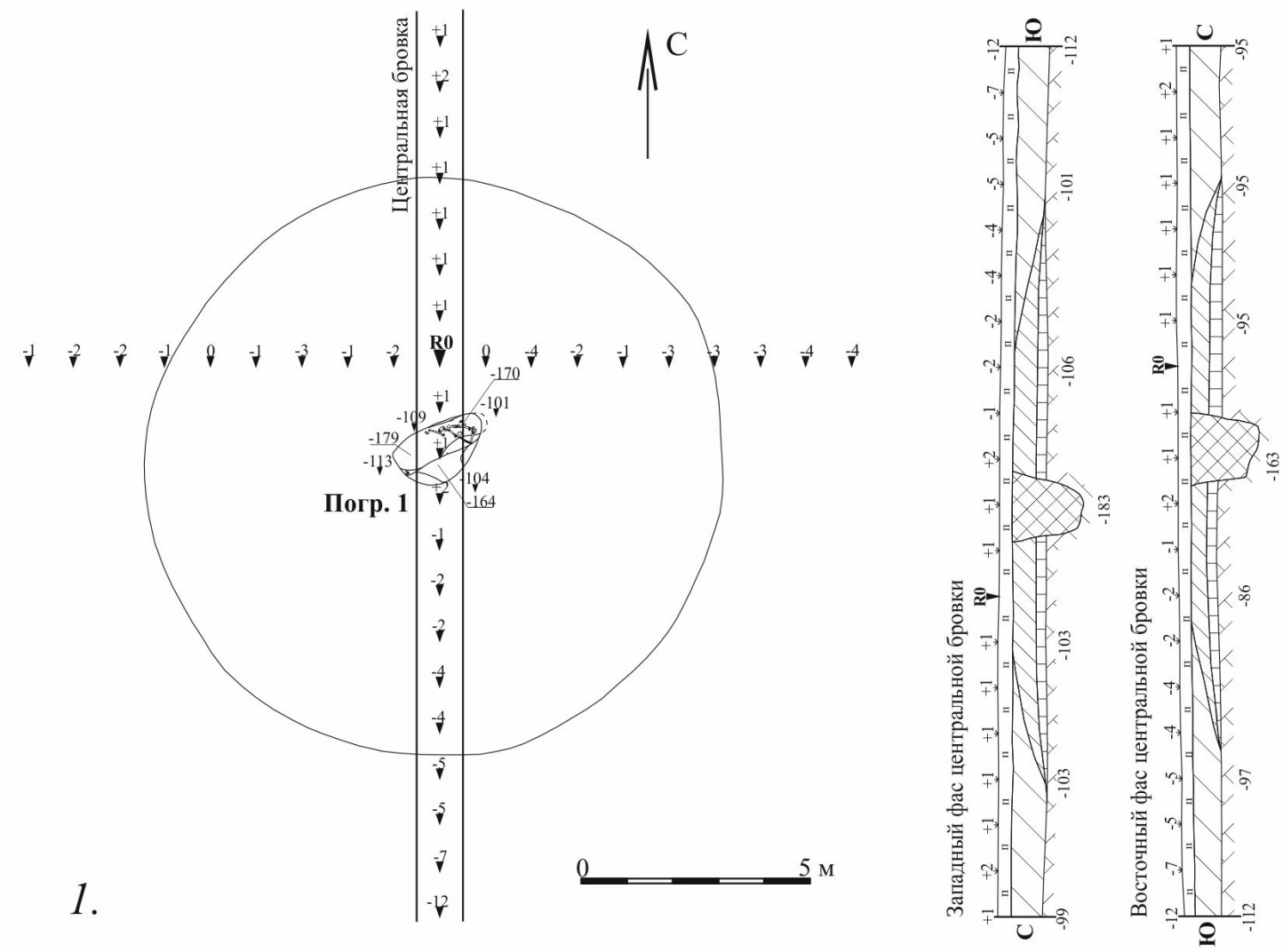

Условные обозначения:
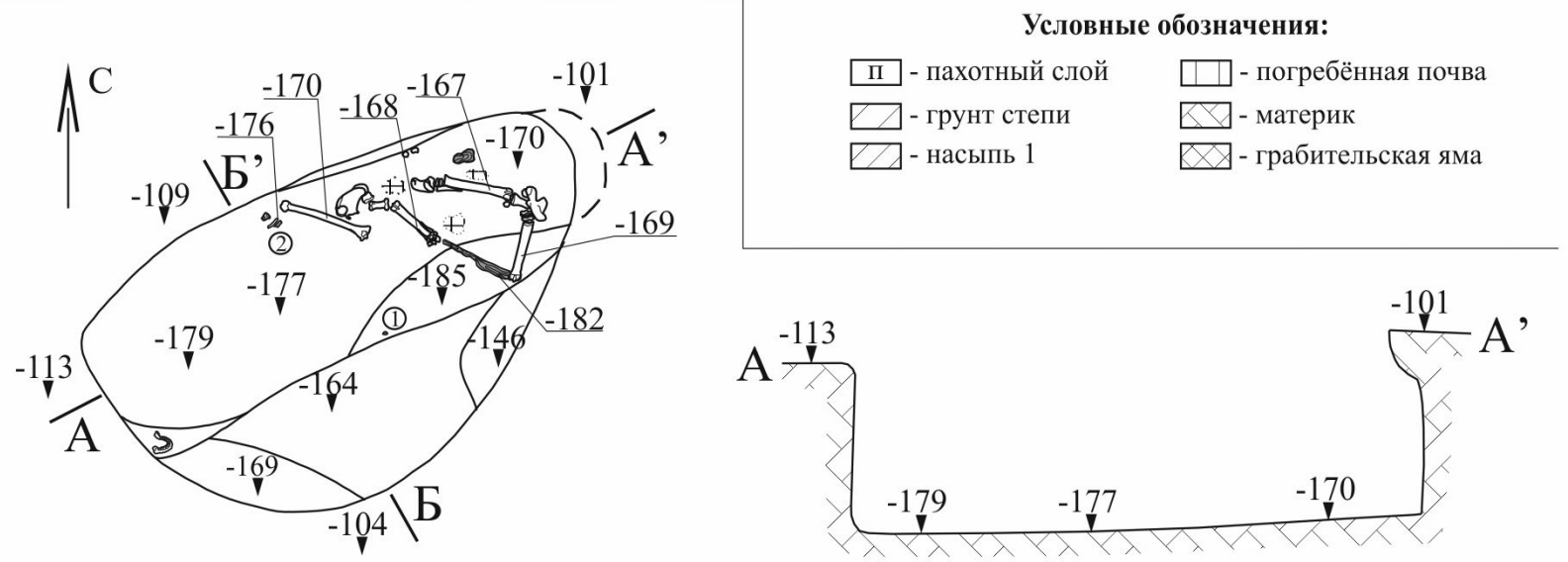

2.

Условные обозначения:

(1) - фрагмент железного предмета

(2) - фрагмент железного предмета

\#- органический тлен

- дерево
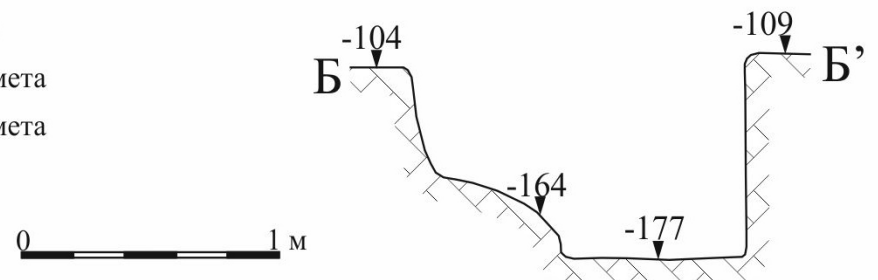

Рис. 6. Курганный могильник Песчанокоп. Курган 7:

1 - план и стратиграфия кургана; 2 - погребение 1

Fig. 6. The burial mound Peschanokop. Mound 7:

1 - plan and the stratigraphy; 2 - burial 1 


\section{ПРИМЕЧАНИЕ}

${ }^{1}$ Авторы выражают благодарность М.В. Кривошееву и В.Ю. Малашеву за помощь в поиске аналогий.

\section{СПИСОК ЛИТЕРАТУРЫ}

Аксенов В. С., Тортика А. А., 2001. Протоболгарские погребения Подонья и Придонечья VIII$\mathrm{X}$ вв.: проблема поливариантности обряда и этноисторической интерпретации // Степи Европы в эпоху средневековья : (Труды по археологии). Т. 2. Хазарское время. Донецк : Изд-во ДонНУ. С. 191-218.

Безуглов С. И., 2008. Курганные катакомбные погребения позднеримской эпохи в нижнедонских степях // МИАР. Вып. 10: Проблемы современной археологии (сб. памяти Владимира Алексеевича Башилова). М. : Таус. С. 284-301.

Виноградов В. Б., 1965. Сиракский союз племен на Северном Кавказе // Советская археология. № 1. C. 108-121.

Гугуев Ю. К., Малашев В. Ю., Рылов В. Г., 2017. Керамический импорт из Центрального Предкавказья в Танаисе в середине III в. н.э. (по результатам минералого-петрографических исследований) // Нижневолжский археологический вестник. Т. 16, № 1. С. 45-61.

Гущина И. И., Засецкая И. П., 1992. К вопросу о хронологии и происхождении «Золотого кладбища» в Прикубанье (по материалам раскопок Н.И. Веселовского) // Проблемы хронологии сарматской культуры. Саратов : Изд-во Сарат. ун-та. С. 45-67.

Засецкая И. П., 2008. Сарматы в Северном Причерноморье // Сокровища сарматов. Каталог выставки. К 100-летию со дня рождения академика Бориса Борисовича Пиотровского. СПб. ; Азов : Изд-во Азов. музея-заповедника. С. 4-14.

Косяненко В. М., 1989. Хронология сероглиняной керамики некрополя Кобякова городища (раскопки 1956-1962 гг.) // Известия Ростовского областного музея краеведения. Вып. 6. Ростов н/Д : Рост. кн. изд-во. С. 4-41.

Косяненко В. М., 2008. Некрополь Кобякова городища (по материалам раскопок 1956-1962 гг.) // Донские древности. Вып. 9. Азов : Азов. музей-заповедник. 544 с.

Марченко И. И., 1996. Сираки Кубани (по материалам курганных погребений Нижней Кубани). Краснодар : Изд-во Кубан. гос. ун-та. 340 с.

Матюхин А. Д., 1991. Новое позднесарматское погребение в лесостепном Саратовском право- бережье // Археология Восточно-Европейской степи. Вып. 2. Саратов : Изд-во СГУ. C. $135-152$.

Мошкова М. Г., 1980. К вопросу о месте производства некоторых групп сарматской лощеной керамики // Краткие сообщения института археологии. Вып. 162. С. 45-52.

Отчет Императорской археологической комиссии за 1898 год, 1901. СПб.

Смирнов К. Ф., 1972. Сарматские катакомбные погребения Южного Приуралья - Поволжья и их отношение к катакомбам Северного Кавказа // Советская археология. № 1. С. 73-81.

Смирнов К. Ф., 1974. Сарматы Нижнего Поволжья и междуречья Дона и Волги в IV в. до н.э. II в. н.э. (историко-археологический очерк) // Советская археология. № 3. С. 33-44.

Флерова В. Е., 2001. Подкурганные погребения восточноевропейских степей и пути сложения культуры Хазарии // Степи Европы в эпоху средневековья : (Труды по археологии). Т. 2. Хазарское время. Донецк : Изд-во ДонНУ. C. $163-190$.

Яценко С. А., Вдовченков Е. В., 2013. Ограбление сарматских курганов в древности: методы и цели // Нижневолжский археологический вестник. Вып. 13. С. 78-90.

\section{СПИСОК СОКРАЩЕНИЙ}

AВЕС - Археология Восточно-Европейской степи. АЭС - атомная электростанция.

ВЛ - высоковольтная линия.

ГАУК РО - Государственное автономное учреждение культуры Ростовской области.

ГБУК ВО - Государственное бюджетное учреждение культуры Воронежской области.

ГИМ - Государственный исторический музей.

ДонНУ - Донецкий национальный университет.

МИАР - Материалы и исследования по археологии России.

ОАО - Открытое акционерное общество.

ООО-Общество с ограниченной ответственностью. ПС- подстанция.

РГУ - Ростовский государственный университет.

СГУ - Саратовский государственный университет.

\section{REFERENCES}

Aksyonov V.S., Tortika A.A., 2001. Protobulgarian Interments at the Don and the Seversky Donets Basins in the $8^{\text {th }}-10^{\text {th }} \mathrm{cc}$. The Problem of Multivariance Rite and Ethnohistorical Interpretation. Stepi Evropi 
$v$ epohu srednevekovja (Trudi po arheologii), vol. 2. Khazarian times. Donetsk, Donetsk National university Publ., pp. 191-218 (in Russian).

Bezuglov S.I., 2008. The catacomb burials from the burial mounds of Late Roman period in the Lower Don steppes. Materiali i issledovanija po arheologii Rossii, vol. 10. Problemi sovremennoj arheologii (sbornik pam'ati Vladimira Alexejevicha Bashilova). Moscow, Taus Publ., pp. 284-301. (in Russian).

Vinogradov V.B., 1965. The siraks' union of the tribes in the North Caucasus. Sovetskaja arheologija, no. 1, pp. 108-121.

Guguev Yu.K., Malashev V.Yu., Rylov V.G., 2017. Pottery Import from Central Ciscaucasia at Tanais in the Middle of the $3^{\text {rd }}$ Century Ad (Based on Mineralogical and Petrographic Studies). The Lower Volga Archaeological Bulletin, vol. 16, no. 1, pp. 45-61. (in Russian).

Guschina I.I., Zasetskaja I.P., 1992. To the question about the chronology and origin of the "Golden cemetery" in the Kuban region (based on excavations of N.I. Veselovsky). Problemi hronologii sarmatskoj kulturi. Saratov, Saratov University Publ., pp. 45-67. (in Russian).

Zasetskaja I.P., 2008. The Sarmatians in the North Pontic area. Sokrovischa sarmatov. Katalog vistavki. $K$ stoletiju so dnja rozhdenija akademika Borisa Borisovicha Piotrovskogo. SanktPetersburg, Azov, Azov Museum-Reservation Publ., pp. 4-14. (in Russian).

Kosyanenko V.M., 1989. The chronology of grey ware from the necropolis of the Kobyakovo habitation site (excavations of 1956-1962). News of the Rostov regional museum of local history, iss. 6 . Rostov-on-Don, Rost. kn. izd-vo, pp. 4-41. (in Russian).
Kosyanenko V.M., 2008. Necropolis Kobyakov settlement (on materials of excavations 19561962). Azov. 544 p.

Marchenko I.I., 1996. The Siraks of the Kuban Region (based on the materials of the Lower Kuban region's burial mounds). Krasnodar, Kuban' University Publ. 340 p. (in Russian).

Matyuhin A.D., 1991. The new Late sarmatian burial on the forest-steppe zone on Saratov region's right Volga river bank. Arheologija VostochnoEvropejskoj stepi, iss. 2. Saratov, Saratov University Publ., pp. 135-152. (in Russian).

Moshkova M.G., 1980. To the question of some sarmatian glossed pottery groups' production site. Brief communications of the Institute of archaeology, iss. 162, pp. 45-52. (in Russian).

Report of the Imperial archaeological Commission for 1898, 1901. Sankt-Petersburg. (in Russian).

Smirnov K.F., 1972. The sarmatian catacomb burials from South Ural and Volga regions and their relationship with North Caucasian catacombs. Sovetskaja arheologija, no. 1. pp. 73-81.

Smirnov K.F., 1974. The Sarmatians of the Lower Volga region and the Don and the Volga interfluve, in the IV century BC - II century ad (historicalarcheological essay). Sovetskaja arheologija, no. 3, pp. 33-44.

Flyorova V.Ye., 2001. Tumulus Interments in the Steppes of Eastern Europe and the ways of Khazaria's Culture Formation. Stepi Evropi v epohu srednevekovja (Trudi po arheologii), vol. 2. Khazarian times. Donetsk, Donetsk National university Publ., pp. 163-190. (in Russian).

Yatsenko S.A., Vdovichenkov E.V., 2013. Looting Sarmatian Kurgans in Ancient Times: Methods and Purposes. The Lower Volga Archaeological Bulletin, vol. 13, pp. 78-90. (in Russian).

\section{Information about the Authors}

Yuriy Yu. Kargin, Candidate of Sciences (History), Head of Research Service of Archaeological expedition Ltd., Kolkhozny Cross., 11a, 346580 Rodionovo-Nesvetayskaya Village, Rostov-on-Don Region, Russian Federation, karginyy@mail.ru.

Vasiliy V. Mataev, Candidate of Sciences (Pedagogy), Specialist-Archaeologist, Archaeological expedition Ltd., Kolkhozny Cross., 11a, 346580 Rodionovo-Nesvetayskaya Village, Rostov-on-Don Region, Russian Federation, legenda@vspu.ru.

Aleksey V. Surkov, Candidate of Sciences (History), Researcher, Center of the security archaeological investigations Ltd., Prosp. Leninsky, 119L, korp. 35A, 394033 Voronezh, Russian Federation, surkovarh@mail.ru. 
Yu.Yu. Kargin, V.V. Mataev, A.V. Surkov. Sarmatian and Early Medieval Burial Mounds of the East Azov Region

\section{Информация об авторах}

Юрий Юрьевич Каргин, кандидат исторических наук, начальник научной службы ООО «Археологическая экспедиция», пер. Колхозный, 11a, 346580 сл. Родионово-Несветайская, Ростовская область, Российская Федерация, karginyy@mail.ru.

Василий Владимирович Матаев, кандидат педагогических наук, специалист-археолог ООО «Археологическая экспедиция», пер. Колхозный, 11a, 346580 сл. Родионово-Несветайская, Ростовская область, Российская Федерация, legenda@vspu.ru.

Алексей Владимирович Сурков, кандидат исторических наук, научный сотрудник ООО «Центр охранных археологических исследований», просп. Ленинский, 119Л, помещение 35А, 394033 г. Воронеж, Российская Федерация, surkovarh@mail.ru. 